\title{
Diversity- and density-mediated allelopathic effects of resident plant communities on invasion by an exotic plant
}

\author{
Michael Opoku Adomako • Lei Ning • Min Tang • \\ Dao-Lin Du • Mark van Kleunen • Fei-Hai Yu
}

\begin{abstract}
Aims Resident plants can exert allelopathic effects on introduced exotic plants, and resistance to exotic plant invasions usually increases with diversity and density of the resident plant communities. We hypothesize that allelopathic effects increase with increasing diversity and density of the community, and thereby contribute to the community's resistance against invaders.
\end{abstract}

Responsible Editor: Hans Lambers.

M. O. Adomako $\cdot$ M. Tang $\cdot$ F.-H. Yu

Institute of Wetland Ecology \& Clone Ecology, Taizhou University, Taizhou 318000 Zhejiang Province, China

M. O. Adomako

e-mail:moadomako@gmail.com

M. Tang

e-mail: tangminnn@126.com

M. O. Adomako $\cdot$ M. Tang • M. van Kleunen · F.-H. Yu ( $\bowtie)$ Zhejiang Provincial Key Laboratory of Plant Evolutionary Ecology and Conservation, Taizhou University, Taizhou 318000 Zhejiang Province, China

e-mail: feihaiyu@126.com

M. van Kleunen

e-mail: mark.vankleunen@uni-konstanz.de
Methods To test these hypotheses, we conducted two greenhouse experiments in which we grew five individuals of the exotic invasive plant Solidago canadensis in pots without residents and in artificially assembled resident plant communities either with two levels of diversity ( 4 or 8 resident plant species) or two levels of density ( 8 or 32 individuals, representing 8 species). We used activated carbon as the allelopathy-neutralizer treatment in both the diversity and the density experiment.

M. O. Adomako • D.-L. Du

Institute of Environment and Ecology, Academy of Environmental Health and Ecological Security, School of the Environment and Safety Engineering, Jiangsu University, Zhenjiang 212013 Jiangsu Province, China

D.-L. Du

e-mail: daolindu@163.com

L. Ning • F.-H. Yu

School of Nature Conservation, Beijing Forestry University, Beijing 100083, China

L. Ning e-mail: lei198729@126.com

M. van Kleunen

Ecology, Department of Biology, University of Konstanz, Universitätsstrasse 10, D-78464 Constance, Germany 
Results In the absence of activated carbon, $S$. canadensis grew worse in the presence of residents, and when diversity or density of the residents increased. These negative effects, however, largely disappeared in the presence of activated carbon, and at the highest resident density $S$. canadensis even performed better with than without activated carbon.

Conclusions Low invasibility of species-rich and dense plant communities is likely to be at least in part associated with increased allelopathy. Our study provides the first evidence that increasing allelopathy could be a mechanism underlying the diversity and density effects on community invasibility.

Keywords Alien plant - Allelochemicals · Competitive dominance - Complementarity effect - Sampling effect . Selection effect $\cdot$ Species richness

\section{Introduction}

Biological invasions have received much consideration due to the potential threats they impose on ecosystem processes and functioning (Pearson et al. 2018; Petruzzella et al. 2018). Successful plant invasions are attributed to the interaction between the exotic plants and the resident plant communities (Gallien and Carboni 2017; Theoharides and Dukes 2007). Exotic invasive plants may outperform native species due to the absence of their natural enemies in the introduced range (Aguilera 2011; Callaway and Ridenour 2004; Keane and Crawley 2002). Moreover, invasive plants are regarded to possess superior characteristics, such as high competitive ability, efficient absorption and utilization of resources (Baker 1965; Levine 2000; Petruzzella et al. 2018; van Kleunen et al. 2015), a ruderal strategy (Guo et al. 2018) and capability of clonal growth (Parsons and Cuthbertson 2001; Song et al. 2013; Wang et al. 2017). A large body of studies has also elaborated on the allelopathic potential of invasive plants, which may reduce competition by resident plants (Callaway and Ridenour 2004; Dostál 2011; Goel et al. 1989; Prati and Bossdorf 2004; Wardle et al. 1998). However, the resident plants may also produce allelopathic compounds, and it could be that allelopathy of resident plants provides resistance against invaders (Weidenhamer and Romeo 2005). Although this idea was already posed by Rabotnov (1982), it has rarely been tested (Cummings et al. 2012; Hou et al. 2012; Ning et al. 2016; van Kleunen et al. 2018).
Another characteristic of the resident community that might provide resistance against invaders is diversity (Elton 1958). Communities with high species diversity can more fully exploit the available resources (e.g. light, water and nutrients) and space due to niche differentiation and complementarity (Dostál 2011; Emery and Gross 2007; Ortega and Pearson 2005; van Ruijven et al. 2003), leaving less resources and space to potential invaders. This is particularly the case if the community includes different functional groups, such as grasses, nitrogen-fixing forbs and non-nitrogen-fixing forbs. Moreover, diversity increases the stability of a community (Pearson et al. 2018), thereby providing fewer windows of opportunity for establishment of invaders. Furthermore, high plant diversity of communities might lead to a complex food web (Emery and Gross 2007; Zak et al. 2003), with a higher stability and lower invasibility compared to less diverse communities (Emery and Gross 2007). In addition to complementarity effects, communities with high plant diversity may also display a distinct sampling (selection) effect (Emery and Gross 2007; Holmes et al. 2016; Wu et al. 2017; Zhu et al. 2015). For instance, inclusion of a highly competitive $\mathrm{C} 4$ grass species in a resident community was shown to effectively reduce biomass of invading species (Fargione and Tilman 2005). Another mechanism through which species diversity may reduce invasibility of resident communities is that higher species diversity results in a higher diversity of allelopathic compounds, and stronger allelopathy overall. To the best of our knowledge, this hypothesis has never been tested.

The density of plants in a community also determines competition intensity and the efficiency to exploit available resources and space (Naeem et al. 2000; Teixeira et al. 2017; Turnbull et al. 2010; Wu et al. 2017). Denser communities thus should leave less resources and space for potential invaders (Dostál 2011; Dukes 2002; Michelan et al. 2013). Furthermore, a high degree of canopy closure in dense communities may also effectively inhibit seed germination, and seedling and juvenile plant growth of invasive exotic species (Christina et al. 2015; Emery and Gross 2007; Liao et al. 2015; Pearson et al. 2018). This is also supported by the fact that undisturbed communities with a closed canopy are less likely to be invaded by exotic plants compared to frequently disturbed communities with an open canopy (Arroyo et al. 2018; Davis et al. 2000; Sun et al. 2015; Tan et al. 2015). In addition, the effect of density on the 
invasibility of resident plant communities may also be due to increased concentrations of allelopathic compounds. To date, however, no study has tested whether denser communities generate stronger allelopathic effects on invasive exotic plants.

To test the hypotheses that allelopathic effects increase with increasing diversity and density of the community, and thereby contribute to the community's resistance against invaders, we conducted two greenhouse experiments using activate carbon to neutralize allelopathic effects. In one experiment, we planted mesocosm pots with resident grassland communities with different levels of species richness, and in the other we planted mesocosm pots with resident grassland communities with different density levels. In both experiments, we also had control pots without resident grassland communities. Then, the pots were invaded by the exotic plant Solidago canadensis, which is highly invasive in China. Specifically, we addressed the following main questions. (1) Is the allelopathic effect of the resident plant communities on the growth of $S$. canadensis stronger when species richness of the resident communities is higher? (2) Is the allelopathic effect stronger when the density of the plant individuals in the resident communities is higher?

\section{Materials and methods}

Plant species

Solidago canadensis L. (Asteraceae), native to North America, is listed as an invasive weed in many countries (Abhilasha et al. 2008; Zhang et al. 2009). It was introduced to China as an ornamental plant in 1935 and has spread into the wild since 1980 (Li et al. 2001). Solidago canadensis can grow over $1.5 \mathrm{~m}$ tall, and can reproduce sexually by producing large amounts of seeds. As it produces a branched rhizome system belowground from which multiple erect stems emerge, it can also reproduce asexually. The seeds are small and dispersed by wind. Due to its tall stature and extensive clonal growth, the species shows strong competitive ability and can displace native plant species, especially in habitats disturbed by human activities (Chen et al. 2012; Li et al. 2010). In Europe, it was shown that $S$. canadensis may have allelopathic effects on native plant species (Abhilasha et al. 2008). In the middle of November 2015 , seeds of $S$. canadensis were collected in a suburb of Hangzhou, Zhejiang Province, China. On March 1, 2016, seeds of $S$. canadensis were sown in boxes (length: $38 \mathrm{~cm}$; width: $28 \mathrm{~cm}$; height: $14 \mathrm{~cm}$ ) filled with river sand. On May 2, 2016, seedlings of similar size were selected for use in the two experiments described below.

We used a total of eight species that are commonly found in grasslands in China to construct resident plant communities. To increase functional diversity and have realistic communities, we chose the eight grassland species in such a way that they belonged to three different functional groups, i.e. four grasses (Festuca elata Keng ex E. Alexeev, Poa pratensis L., Bromus inermis Leyss and Lolium perenne L.), two legume forbs (Trifolium pratense L. and Trifolium repens L.) and two non-legume forbs (Cichorium intybus L. and Ixeridium sonchifolium (Maxim.) Shih). It should be noted that the two Trifolium species are not native to China, but have been present there for at least two centuries (http://www. chinaias.cn/wjPart/SpeciesSearch.aspx? speciesType=3 ), last visited on April 5, 2019) and are now so common in China that they are part of many resident grassland communities. To make the results more representative, we did not a priori select resident species with known allelopathic effects. However, a posteriori literature searches revealed that at least one of the species, $T$. pratense, has known allelopathic effects (Liebman 2006; Lou et al. 2016). The seeds of the eight species were bought from Beijing Zhongshu Dasen Seed Co. Ltd. in Beijing, China. On April 1, 2016, one month after sowing the seeds of $S$. canadensis, seeds of the eight grassland species were sown in boxes (length: 38 $\mathrm{cm}$; width: $28 \mathrm{~cm}$; height: $14 \mathrm{~cm}$ ) filled with river sand. All eight species successfully germinated within one week.

\section{Experimental design}

We conducted two greenhouse experiments to test the effects of species diversity and density of plant individuals, respectively, on allelopathic potential of the resident plant communities against the invasive herb S. canadensis.

Species-diversity experiment: To test the effect of species diversity on allelopathic potential against $S$. canadensis, we carried out an experiment with three levels of resident-species diversity $(0,1$ or 4 plant species) crossed with two levels of activated carbon addition (with or without). For the 0-, 1- and 4-species 
treatments, each pot $(23 \mathrm{~cm}$ in diameter and $22 \mathrm{~cm}$ in height) was planted with no seedlings of resident species, 12 seedlings of the same resident species or 12 seedlings of four resident species (each species having three seedlings) surrounding the central area where seedlings of the invasive species $S$. canadensis were planted (Appendix Fig. 1). The 12 seedlings were arranged at equal intervals in two circles around the central area of the pot, with eight seedlings in the outer circle and four seedlings in the inner circle (Appendix Fig. 1). For the 4-species treatment, each species occurred twice in the outer circle and once in the inner circle, and seedlings of the same species were not adjacent (Appendix Fig. 1). The four species used in this experiment were $B$. inermis, $L$. perenne, $T$. repens and $C$. intybus. Activated carbon can absorb allelopathic substances from plant roots and thereby supposedly neutralizes the allelopathic effects (Lau et al. 2008; Weißhuhn and Prati 2009). For half of the pots, we mixed the soil with $20 \mathrm{ml} \mathrm{L}^{-1}$ activated carbon (CASNO: 7440-44-0, Tianjin Woersi Chemical Corporation), and for the other half no activated carbon was added. The amount of activated carbon added followed Lau et al. (2008) and Weißhuhn and Prati (2009). The soil was a 1:1 mixture of quartz sand and vermiculite, with $3.5 \mathrm{~g} \mathrm{~L}^{-1}$ slow-release fertilizer (Osmocote, $\mathrm{N}: \mathrm{P}: \mathrm{K}: \mathrm{MgO}=16: 9: 12: 2)$. We used a non-organic substrate to reduce the side effect of activated carbon on soil nutrient release from organic matter, as it has been reported that the addition of activated carbon could trigger organic nutrient release (Weißhuhn and Prati 2009). On April 23, 2016, plants of the four resident species were transplanted into the pots. One week later, on May 2, 2016, five seedlings of $S$. canadensis were transplanted into the centre of each pot. Initial height of the $S$. canadensis seedlings was $0.91 \pm 0.02 \mathrm{~cm}$ (mean \pm $\mathrm{SE}$ ). Each species and diversity level were replicated six times, making a total of 72 pots, i.e. $[1(0$-species $)+4$ $(1$-species $)+1$ (4-species) $) \times 2$ (activated carbon) $\times 6$ (replications).

Density experiment: To test the effect of plant density, we conducted an experiment with three levels of resident-plant density (none, low density and high density) crossed with two levels of activated carbon addition (with or without). In the 'none' level, no resident plants were grown. In the low- and high-density levels, each pot ( $23 \mathrm{~cm}$ in diameter and $22 \mathrm{~cm}$ in height) was planted with 8 and 32 seedlings of the eight resident grassland species, respectively. Thus, each of the low- and high-density pots had eight resident species, each with 1 or 4 seedlings, respectively. In half of the pots, we had mixed the soil with $20 \mathrm{ml} \mathrm{L}^{-1}$ activated carbon (CASNO: 7440-44-0) and in the other half, no activated carbon had been added. The substrate used was the same as the one used in the species-diversity experiment. On April 23, 2016, seedlings of the eight resident species were transplanted into the pots. On May 2, 2016, five seedlings of $S$. canadensis were transplanted into the center of each pot. Initial height of these seedlings was $0.96 \pm 0.02 \mathrm{~cm}$ (mean $\pm \mathrm{SE}$ ). Each treatment was replicated six times, resulting in a total of 36 pots.

Both experiments were carried out in a greenhouse of Beijing Forestry University, China $\left(40^{\circ} 40^{\prime} 32^{\prime \prime} \mathrm{N}\right.$, $116^{\circ} 20^{\prime} 24^{\prime \prime}$ E). As all pots were placed within a small area where spatial heterogeneity in microclimatic conditions was expected to be minimal, we re-arranged the pots randomly only twice during the ten weeks of the experiments. Plants were watered daily to keep the soil moist. During the whole period of the experiment, daily mean temperature in the greenhouse was $24.8 \pm 0.5^{\circ} \mathrm{C}$ (SE), and light transmittance into the greenhouse was c. $60 \%$. The average light period was $14.5 \mathrm{~h}$ per day; no additional lighting was provided. No plants of $S$. canadensis died during the experiment, and the resident plants that died during the first week were replaced immediately.

\section{Measurements and harvest}

On July 2, 2016, in each pot we recorded the height of each $S$. canadensis plant to calculate the mean height. We harvested the roots, stems and leaves separately for the five $S$. canadensis plants in each pot. Total leaf area of $S$. canadensis was obtained using WinFOLIA Pro 2004a (Regent Instruments, Inc., Canada). Aboveground and belowground biomass of the resident plant community was also harvested. All samples were dried at $70{ }^{\circ} \mathrm{C}$ for at least $72 \mathrm{~h}$ and then weighed.

\section{Statistical analyses}

We used two-way ANOVAs to test the effects of activated carbon addition (with vs. without) and residentcommunity presence $\&$ richness ( 0 vs. 1 vs. 4 resident plant species) for the species-diversity experiment or resident-community presence $\&$ density ( 0 vs. 8 vs. 32 resident plant individuals) for the density experiment on the growth (total biomass, root biomass, stem biomass, 
leaf biomass, height and total leaf area) of the invasive plant $S$. canadensis. For the species diversity experiment, following ANOVA, we further used two planned contrasts to separate the effect of resident-community presence \& richness into the effect of resident-species presence $[0$ species vs. ( 1 species +4 species $)]$ and the effect of resident-species richness (1 vs. 4 species) (Sokal and Rohlf 1995). We also did two planned contrasts to separate the activated carbon addition $\times$ resident-community presence $\&$ richness interaction into the activated carbon addition $\times$ resident-species presence interaction and the activated carbon addition $\times$ resident-species richness interaction (Sokal and Rohlf 1995). Similarly, for the density experiment, we used two planned contrasts to separate the effect of residentcommunity presence $\&$ density into the effect of resident-species presence [0 individuals vs. ( 8 individuals +32 individuals)] and the effect of residentindividual density ( 8 vs. 32 individuals) and also two planned contrasts to separate the activated carbon addition $\times$ resident-community presence $\&$ density interaction into the activated carbon addition $\times$ resident-species presence interaction and the activated carbon addition $\times$ resident-individual density interaction. All data were transformed to $\log _{10}$ to increase normality and/or homogeneity of variance. SAS 9.1 was used for all the analyses (SAS Institute Inc. 2004).

\section{Results}

Effects of resident-plant species diversity on invasive plant growth

The presence of resident plant species markedly decreased all growth measures (total, root, stem and leaf biomass, height and total leaf area) of the invasive plant S. canadensis (Fig. 1, Table 1: effect of resident presence). Increasing species richness (from 1 to 4 species) of the resident plant community decreased total biomass, root biomass, leaf biomass and total leaf area of S. canadensis without activated carbon addition, but tended to increase the values of these traits or had no impact with activated carbon (Fig. 1, Table 1: effect of activated carbon addition $\times$ resident richness). Averaged across all diversity treatments, activated carbon addition significantly decreased biomass and height, and marginally significantly decreased total leaf area of S. canadensis (Table 1, Fig. 1 ). However, this negative effect of activated carbon addition on total biomass, root biomass, leaf biomass and total leaf area was stronger when the resident community consisted of 1 than of 4 species (Fig. 1), as indicated by the significant or marginally significant interaction effect of activated carbon addition $\times$ resident species richness (i.e. $A \times R R$, Table 1).

Effects of resident-plant individual density on invasive plant growth

Compared to the absence of resident plants, the presence of resident plants significantly decreased all growth measures of the invasive plant $S$. canadensis in the absence of activated carbon, but had little impact in the presence of activated carbon addition (Fig. 2, Table 2: main effect of resident presence and effect of activated carbon addition $\times$ resident presence). The growth of $S$. canadensis was also significantly lower when the resident community consisted of 32 instead of 8 plant individuals without activated carbon addition, but such effects diminished with activated carbon addition (Fig. 2, Table 2: effect of activated carbon addition $\times$ resident density). The effect of activated carbon addition on the growth of S. canadensis depended on whether the resident plant community was absent or present (Table 2: effect of activated carbon addition $\times$ resident presence) and also on the density of the resident plant communities (Table 2: effect of activated carbon addition $\times$ resident density). The effect of activated carbon addition was more negative when the resident plant community was absent than when it consisted of 8 plant individuals, and became positive when it consisted of 32 individuals (Fig. 2).

\section{Discussion}

It has long been shown that species-rich communities and undisturbed communities with closed, dense vegetation are less prone to exotic plant invasions (Callaway et al. 2005; Elton 1958; Naeem et al. 2000; Vojik and Boublik 2018). Several hypotheses have been proposed to explain such diversity and density effects on the invasibility of resident plant communities; for instance, species-richer or dense communities can make better use of resources and thus leave less resources for invasive species (Fargione and Tilman 2005; van Ruijven et al. 2003; Zhu et al. 2015). We also found that species- 

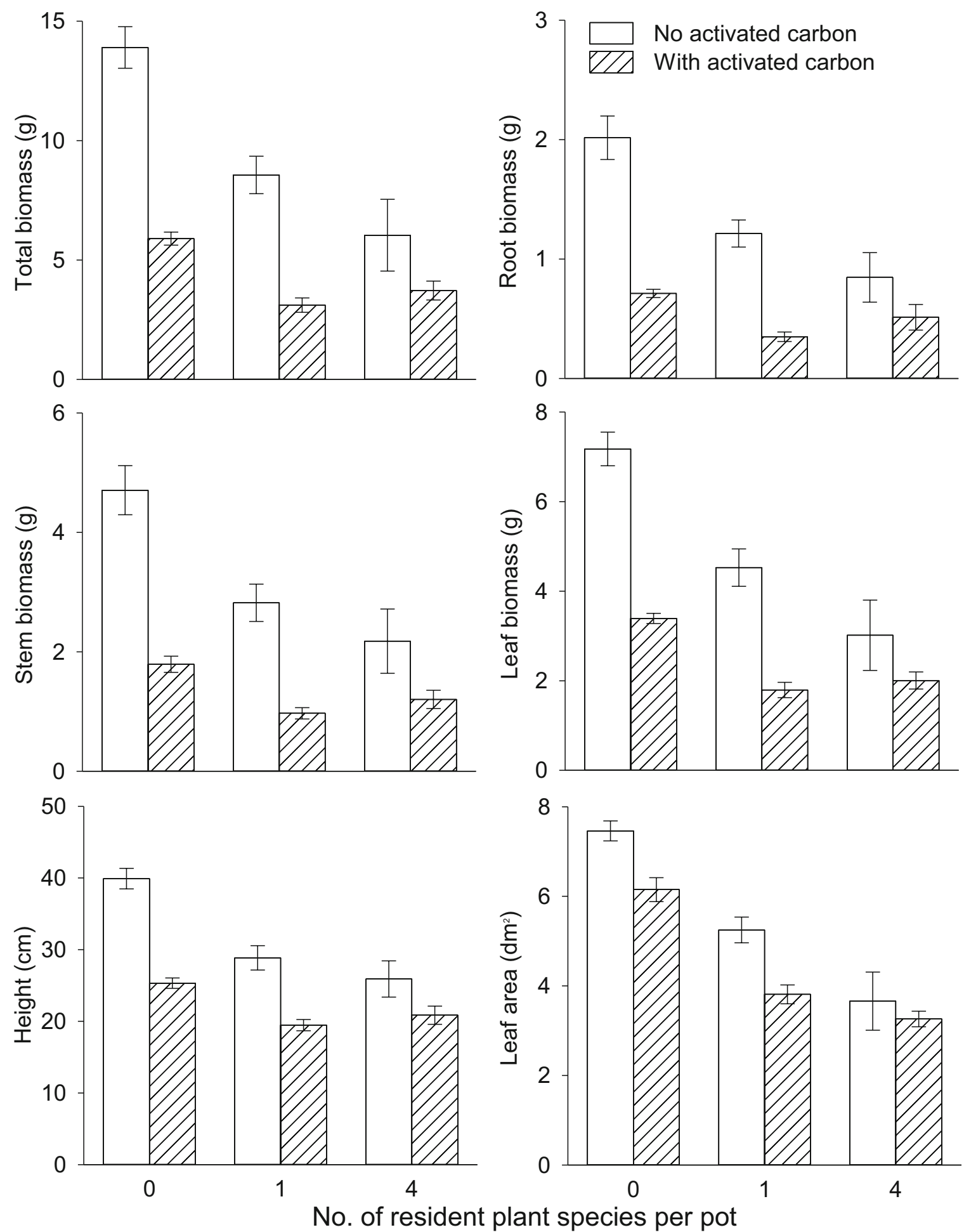

Fig 1 Biomass, height and total leaf area of Solidago canadensis growing alone or in the resident communities with two levels of species diversity with or without activated carbon. Mean \pm SE are given

diversity and density provided resistance against invasion by $S$. canadensis. However, these effects largely disappeared when activated carbon was mixed into the soil. Although activated carbon may have other effects besides adsorption of allelochemicals (Kabouw et al.
2010; Lau et al. 2008; Wurst et al. 2010), and could also remove allelopathic effects of the invader on the residents as well as autotoxicity of the plants, our results could indicate that increasing species diversity and plant density may increase the allelopathic effects of resident 
Table 1 Results of ANOVAs for effects of activated carbon addition (A) and resident community presence \& richness (R, i.e. 0 vs. 1 vs. 4 plant species) on the growth of Solidago canadensis

\begin{tabular}{|c|c|c|c|c|c|c|c|}
\hline Effect & $\mathrm{DF}$ & Total biomass & Root biomass & Stem biomass & Leaf biomass & Plant height & Leaf area \\
\hline Activated carbon (A) & 1,66 & $23.60^{* * *}$ & 35.50 **** & $23.84^{* * * *}$ & $15.27^{* * * *}$ & $17.65^{* * * *}$ & $3.63^{\#}$ \\
\hline Resid. presence \& richness (R) & 2,66 & $9.49^{* * *}$ & $9.80^{* * * *}$ & $7.57^{* *}$ & $9.40^{* * * *}$ & $7.06^{* * *}$ & $18.46^{* * *}$ \\
\hline Resident presence (RP) & 1,66 & $18.53^{* * * *}$ & $17.95^{* * * *}$ & $13.76^{* * * *}$ & $18.77^{* * * *}$ & $12.85^{* * * *}$ & $35.17^{* * * *}$ \\
\hline Resident richness (RR) & 1,66 & $0.38^{\mathrm{ns}}$ & $<0.01^{\mathrm{ns}}$ & $<0.01^{\mathrm{ns}}$ & $1.26^{\mathrm{ns}}$ & $<0.01^{\mathrm{ns}}$ & $8.99^{* *}$ \\
\hline $\mathrm{A} \times \mathrm{R}$ & 2,66 & $2.53^{\#}$ & $3.48^{*}$ & $1.32^{\mathrm{ns}}$ & $2.65^{\#}$ & $0.63^{\mathrm{ns}}$ & $1.49^{\mathrm{ns}}$ \\
\hline $\mathrm{A} \times \mathrm{RP}$ & 1,66 & $0.39^{\text {ns }}$ & $0.32^{\text {ns }}$ & $0.42^{\mathrm{ns}}$ & $0.39^{\text {ns }}$ & $0.91^{\mathrm{ns}}$ & $0.05^{\mathrm{ns}}$ \\
\hline $\mathrm{A} \times \mathrm{RR}$ & 1,66 & $5.06^{*}$ & $6.90^{*}$ & $2.60^{\mathrm{ns}}$ & $5.31^{*}$ & $0.72^{\mathrm{ns}}$ & $2.90^{\#}$ \\
\hline
\end{tabular}

The effect of $\mathrm{R}$ was further separated into the effect of resident-species presence [RP, i.e. 0 species vs. (1 species +4 species)] and the effect of resident-species richness (RR, i.e. 1 vs. 4 species) by two planned contrasts. Similarly, the effects of A $\times \mathrm{R}$ was further separated into the effect of $\mathrm{A} \times \mathrm{RP}$ and the effect of $\mathrm{A} \times \mathrm{RR}$ by two planned contrasts

F values, degree of freedom (DF) and significance levels $\left({ }^{* * *} P<0.001,{ }^{* *} P<0.01,{ }^{*} P<0.05,{ }^{\#} P<0.1\right.$ and $\left.{ }^{\text {ns }} P>0.1\right)$ are given. Values are in bold when $P<0.05$ and in italics when $0.05<P<0.1$. All data were transformed to $\log _{10}$ before analysis

plant communities on the growth of invasive plants. Thus, increasing allelopathy could be an additional mechanism underlying the negative effects of diversity and density of resident communities on their invasibility.

Many ecological studies on the role of allelopathy in competitive interactions used, like we did, activated carbon as an allelopathy neutralizer (Inderjit and Callaway 2003; Prati and Bossdorf 2004; Ridenour and Callaway 2001). Activated carbon, however, can also have side effects on soil properties, microbes and plant growth (Kabouw et al. 2010; Lau et al. 2008; Wurst et al. 2010). Here, we also found evidence for such undesired side effects, as activated carbon reduced the growth of $S$. canadensis plants when grown in the absence of resident plants. This could, however, also indicate that $S$. canadensis had positive allelopathic effects on its own growth, and that these were neutralized by activated carbon. Nevertheless, evidence for its allelopathy neutralizing effect is provided by the finding that activated carbon severely reduced the negative effect of the residents on the growth of $S$. canadensis. In the species-diversity experiment, we cannot exclude that this is due to negative side effects of activated carbon on the growth of the residents (Appendix Fig. 2), which might have reduced their competitive effects on $S$. canadensis. However, in the density experiment this is an unlikely explanation, because in that experiment there was no effect of activated carbon on the growth of the residents (Appendix Fig. 3). Nevertheless, activated carbon reduced the negative effect of the residents, and at the highest density even promoted the growth of
S. canadensis. Therefore, we conclude that despite its potential side effects, activated carbon most likely acted as an allelopathy neutralizer.

Effects of resident plant diversity on invasive plant growth

Activated carbon addition decreased the growth of the invasive plant species $S$. canadensis in the absence of the resident plant community. However, in the presence of a resident community, the negative effect of activated carbon became weaker when the resident community consisted of four instead of one plant species (Fig. 1). This result provides support for the idea that resident plant communities could impose allopathic effects on exotic plants, as was also suggested by previous studies (Cummings et al. 2012; Hou et al. 2012; Ning et al. 2016; Weidenhamer and Romeo 2005). Moreover, this result supports our first hypothesis stating that with increasing species diversity of the resident plant community, the allelopathic inhibitory effect on the growth of invaders increases.

While at large spatial scales areas rich in native species usually also have more invasive species (Stohlgren et al. 2003), at small spatial scales most studies have shown that increasing species diversity can increase the ability of resident plant communities to resist exotic plant invasions (Petruzzella et al. 2018; Turnbull et al. 2010; Wu et al. 2017). One potential mechanism for the latter is that increasing plantspecies diversity can increase resource-use efficiency and thus result in a more complete exploitation of 

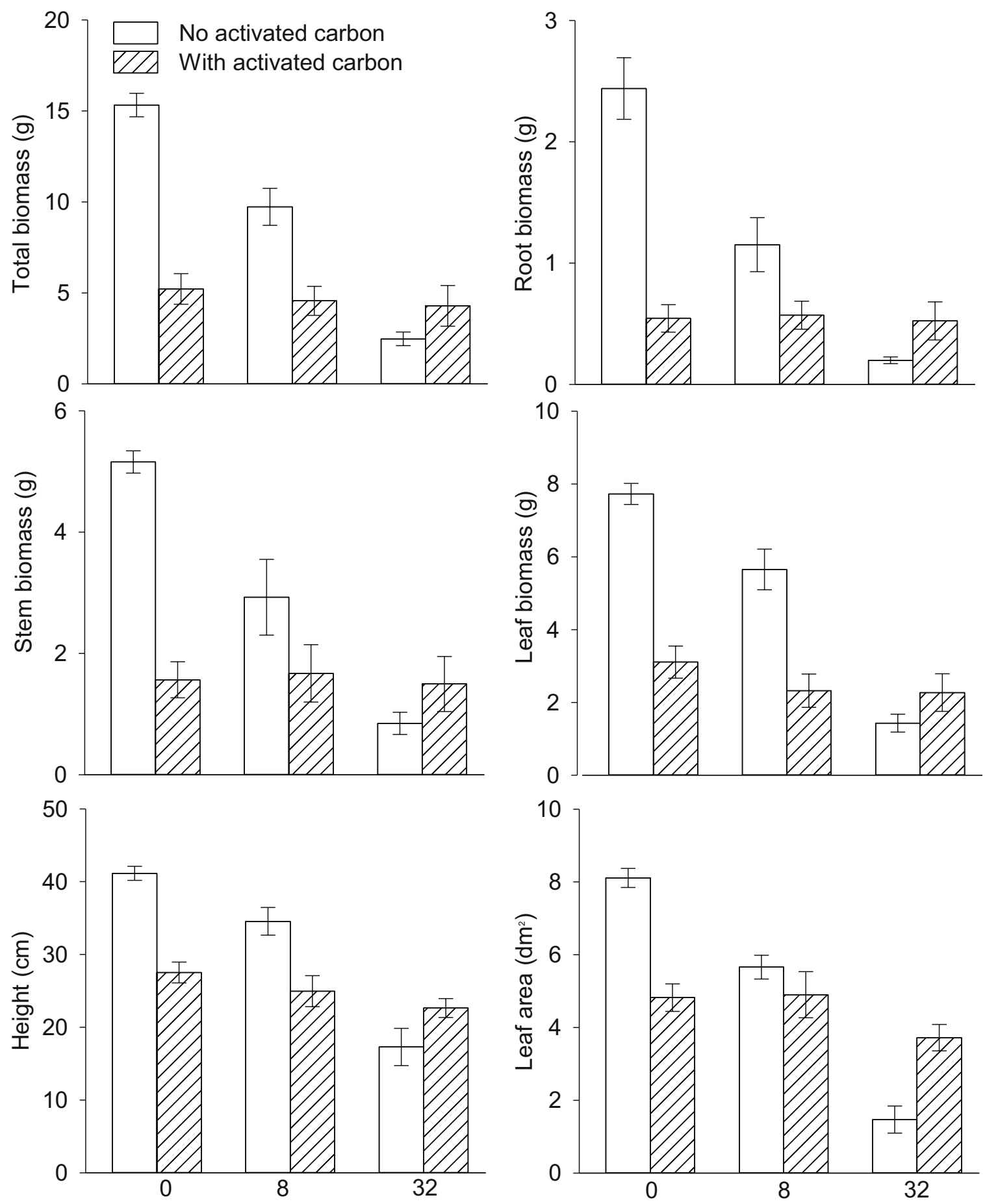

No. of resident plant individuals per pot

Fig. 2 Biomass, height and total leaf area of Solidago canadensis growing alone or in the resident communities with two levels of plant density with or without activated carbon. Means $\pm \mathrm{SE}$ are given

resources through complementarity effects (Davis et al. 2000; Dostál 2011; Emery and Gross 2007; Fargione and Tilman 2005; Grace et al. 2017). This would leave fewer or lower amounts of resources to support the establishment and growth of introduced plants (Davis et al. 2000). Another potential mechanism is that more diverse plant communities may have a higher chance to include at least one plant species with a high competitive ability to effectively suppress the introduced plant species (i.e. a sampling effect) (Petruzzella et al. 2018; Qin et al. 2013; Wardle 2001). One particular example of this mechanism is that species-richer communities may 
Table 2 Results of ANOVAs for effects of activated carbon addition (A) and resident-community presence \& density (R, i.e. 0 vs. 8 vs. 32 plant individuals) on the growth of Solidago canadensis

\begin{tabular}{|c|c|c|c|c|c|c|c|}
\hline Effect & $\mathrm{DF}$ & Total biomass & Root biomass & Stem biomass & Leaf biomass & Plant height & Leaf area \\
\hline Activated carbon (A) & 1,30 & $14.12^{* * * * *}$ & $6.65^{*}$ & $6.07^{*}$ & $15.65^{* * * * *}$ & $3.90^{\#}$ & $2.24^{\mathrm{ns}}$ \\
\hline Resident presence \& density (R) & 2,30 & $23.63^{* * *}$ & $17.49^{* * * *}$ & $10.33^{* *}$ & $25.60^{* * * *}$ & $23.06^{* * * *}$ & $28.62^{* * * *}$ \\
\hline Resident presence (RP) & 1,30 & $24.92^{* * * *}$ & $19.35^{* * * *}$ & $12.59^{* *}$ & $27.99^{* * * *}$ & $22.57^{* * * *}$ & $28.33^{* * * *}$ \\
\hline Resident density (RD) & 1,30 & $22.34^{\text {***** }}$ & $15.64^{* * *}$ & $8.08^{* *}$ & $23.21^{* * * *}$ & $23.55^{* * *}$ & $28.91^{* * * *}$ \\
\hline $\mathrm{A} \times \mathrm{R}$ & 2,30 & $12.89^{* * *}$ & $14.16^{* * *}$ & $6.61^{* *}$ & $12.97^{* * * *}$ & $11.05^{* * * *}$ & $10.57^{* * * *}$ \\
\hline $\mathrm{A} \times \mathrm{RP}$ & 1,30 & $11.04^{* * *}$ & $18.03^{* * *}$ & $8.48^{* * *}$ & $6.40^{*}$ & $7.32^{*}$ & $13.75^{* * * *}$ \\
\hline $\mathrm{A} \times \mathrm{RD}$ & 1,30 & $14.73^{* * * *}$ & $10.29^{* * *}$ & $4.73^{*}$ & $19.54^{* * * *}$ & 14.77 & $7.39^{*}$ \\
\hline
\end{tabular}

The effect of $\mathrm{R}$ was further separated into the effect of resident-species presence [RP, i.e. 0 individuals vs. ( 8 individuals +32 individuals)] and the effect of resident-plant density (RD, i.e. 8 vs. 32 individuals) by two planned contrasts. Similarly, the effects of $\mathrm{A} \times \mathrm{R}$ was further separated into the effect of $\mathrm{A} \times \mathrm{RP}$ and the effect of $\mathrm{A} \times \mathrm{RD}$ by two planned contrasts

F values, degree of freedom (DF) and significance levels $\left({ }^{* * *} P<0.001,{ }^{* *} P<0.01,{ }^{*} P<0.05,{ }^{\#} P<0.1\right.$ and $\left.{ }^{\text {ns }} P>0.1\right)$ are given. Values are in bold when $P<0.05$ and in italics when $0.05<P<0.1$. All data were transformed to $\log _{10}$ before analysis

have plant species that are functionally similar to the invasive plant species, which can greatly enhance the ability of the community to resist exotic plant invasion due to niche overlap (Burke and Grime 1996; Fargione and Tilman 2005; Marraffini and Geller 2015).

It is must be noted that, like any experiment, we cannot extrapolate our results beyond the conditions that we used. For example, soil physico-chemical properties, microbial composition, and propagule pressure of invaders could greatly influence allelochemical interactions among resident and invading species (Inderjit 2001; Schmidt and Ley 1999). Nevertheless, our results suggest that, in addition to the abovementioned complementarity and sampling effects (Fargione and Tilman 2005; Frankow-Lindberg 2012; Levine et al. 2004), increasing species diversity may increase the complementary or the selection effect of allelopathy. In other words, more diverse communities may produce stronger allelopathic effects due to mixing of different allelopathic chemicals produced by different plants or due to the production of a very strong allelopathic chemical by at least one of the species. Indeed, there is evidence that mixtures of different chemicals (of a single species) have stronger negative effects on plant growth than each of the single chemicals (Einhellig 1995; Inderjit and Duke 2003). It is also reasonable to assume that more diverse communities have a higher chance to include species that produce chemicals that have a stronger allelopathic effect (Byun and Lee 2017; Hector et al. 2001; Qin et al. 2013). Therefore, increasing allelopathy with increasing species richness, either due to complementarity or sampling might be one of the mechanisms underlying the finding that species-rich communities are usually more resistant to invasions.

Effects of resident plant density on invasive plant growth

In nature, plant density can vary greatly between different environments, and what is a high density in a temperate, fertile meadow can be quite different from what is a high density in an arid, sandy soil. Not surprisingly, however, we found that with a relative increase in density of the resident community, the growth of the invasive $S$. canadensis decreased. Most other studies on this topic also revealed a negative relationship between invasibility of plant communities and their density, degree of canopy closure or biomass production (Brown and Fridley 2003; Kempel et al. 2013; Vojik and Boublik 2018). Dense communities leave little space and few resources to support additional plant recruitment, and it then obviously becomes difficult for exotic plants to establish. This principle is also well known from agriculture, where studies have demonstrated that there is a positive linkage between high crop density and weed suppression (Parker and Riches 1993; Tollenaar et al. 1994).

Besides the aforementioned mechanisms, increasing plant density of the resident communities may result in a proportional increment of allelopathy. Indeed, like in the diversity experiment, the density experiment also showed a reduced negative effect of activated carbon addition in the presence compared to in the absence of 
resident plants. This again suggests that the resident plant communities imposed an allelopathic effect on the invasive plant $S$. canadensis. Moreover, the effect of activated carbon addition on the growth of $S$. canadensis switched from negative in the lowdensity community to positive in the high-density community, implying that the allelopathic effect of the resident plant community became stronger with increasing plant density. These results thus support our second hypothesis that with increasing density of the resident plant community its allelopathic inhibitory effect on the growth of $S$. canadensis increased.

\section{Conclusions}

Our study provides novel evidence that increasing allelopathy can be a mechanism underlying the diversity and density effects on community invasibility. The design of our species-diversity experiment, however, does not allow us to tell whether the increased allelopathic effect was due to the mixing of different allelopathic chemicals produced by different species (i.e. a complementarity effect) or due to the production of a stronger allelopathic chemical by at least one specific plant species (i.e. a sampling effect). Future studies should be designed to separate such effects. For example, instead of using activated carbon as an allelopathy neutralizer, studies could add allelopathic chemicals (e.g. Weidenhamer et al. 1989) or mixtures thereof. Moreover, it is somewhat elusive to translate the results from a growth study in a simulated plant community to the natural condition where exotic species have to establish and spread (and have an impact) before they are considered invasive. Therefore, longer-term field studies are needed to test whether allelopathy can be a major mechanism of resistance against exotic invaders. Our study shows that the potential is there, and that it may increase with diversity and density of the resident community.

Acknowledgements The work was supported by the National Key Research and Development Program of China (2016YFC1201100) and NSFC (31570413).

\section{References}

Abhilasha D, Quintana N, Vivanco J, Joshi J (2008) Do allelopathic compounds in invasive Solidago canadensis s.l. restrain the native European flora? J Ecol 96:993-1001

Aguilera AG (2011) The influence of soil community density on plant-soil feedbacks: an important unknown in plant invasion. Ecol Model 222:3214-3420

Arroyo AI, Pueyo Y, Luz Giner M, Foronda A, Sanchez-Navarrete P, Saiz H, Alados CL (2018) Evidence for chemical interference effect of an allelopathic plant on neighboring plant species: a field study. PLoS One 13:e0193421

Baker H (1965) Characteristics and modes of origin of weeds. In: Baker HG, Stebbins GL (eds) The Genetics of Colonizing Species. Academic Press, New York

Brown RL, Fridley JD (2003) Control of plant species diversity and community invasibility by species immigration: seed richness versus seed density. Oikos 102:15-24

Burke MJW, Grime JP (1996) An experimental study of plant community invasibility. Ecology 77:776-790

Byun C, Lee EJ (2017) Ecological application of biotic resistance to control the invasion of an invasive plant, Ageratina altissima. Ecol Evol 7:2181-2192

Callaway RM, Ridenour WM (2004) Novel weapons: invasive success and the evolution of increased competitive ability. Front Ecol Environ 2:236-443

Callaway RM, Ridenour WM, Trevor R, Tiffiny W, Vivanco JM (2005) Natural selection for resistance to the allelopathic effects of invasive plants. J Ecol 93:576-583

Chen T, Liu WL, Zhang CB, Wang J (2012) Effects of Solidago canadensis invasion on dynamics of native plant communities and their mechanisms. Chinese J Plant Ecol 36:253-261

Christina M, Rouifed S, Puijalon S, Vallier F, Meiffren G, Bellvert F, Piola F (2015) Allelopathic effect of a native species on a major plant invader in Europe. Sci Nat 102:12

Cummings J, Parker I, Gilbert G (2012) Allelopathy: a tool for weed management in forest restoration. Plant Ecol 213: 1975-1989

Davis MA, Grime JP, Thompson K (2000) Fluctuating resources in plant communities: a general theory of invasibility. $\mathrm{J}$ Ecol 88:528-534

Dostál P (2011) Plant competitive interactions and invasiveness: searching for the effects of phylogenetic relatedness and origin on competition intensity. Am Nat 177:655-667

Dukes JS (2002) Species composition and diversity affect grassland susceptibility and response to invasion. Ecol Appl 12: 602-617

Einhellig FA (1995) Allelopathy: current status and future goals. In: Inderjit DKMM, Einhellig FA (eds) Allelopathy: organisms, processes and applications. American Chemical Society, Washington DC

Elton CS (1958) The ecology of invasions. Methuen, London 
Emery SM, Gross KL (2007) Dominant species identity, not community evenness, regulates invasion in experimental grassland plant communities. Ecology 88:954-964

Fargione JE, Tilman D (2005) Diversity decreases invasion via both sampling and complementarity effects. Ecol Lett 8:604611

Frankow-Lindberg BE (2012) Grassland plant species diversity decreases invasion by increasing resource use. Oecologia 169:793-802

Gallien L, Carboni M (2017) The community ecology of invasive species: where are we and what's next? Ecography 40:335352

Goel U, Saxena DB, Kumar B (1989) Comparative study of allelopathy as exhibited by Prosopis juliflora Swartz and Prosopis cineraria (L.) Druce. J Chem Ecol 15:591-600

Grace JB, Harrison S, Cornell H (2017) Is biotic resistance enhanced by natural variation in diversity? Oikos 126:14841492

Guo W-Y, van Kleunen M, Winter M, Weigelt P, Stein A, Pierce S, Pergl J, Moser D, Maurel N, Lenzner B, Kreft H, Essl F, Dawson W, Pyšek (2018) The role of adaptive strategies in plant naturalization. Ecol Lett 21: 1380-1389

Hector A, Dobson K, Minns A, Bazeley-White E, Lawton J (2001) Community diversity and invasion resistance: an experimental test in a grassland ecosystem and a review of comparable studies. Ecol Res 16:819-831

Holmes C, Figary S, Schulz K, Caceres C (2016) Effects of diversity on community assembly in newly formed pond communities. Ecosphere 7:e1377

Hou Y, Peng S, Ni G, Chen L (2012) Inhibition of invasive species Mikania micrantha H.B.K. by native dominant trees in China. Allelopath J 29:307-314

Inderjit (2001) Soil: environmental effects on allelochemical activity. Agron J 93:79-84

Inderjit, Callaway R (2003) Experimental designs for the study of allelopathy. Plant Soil 256:1-11

Inderjit, Duke SO (2003) Ecophysiological aspects of allelopathy. Planta 217:529-539

Kabouw P, Nab M, van Dam N (2010) Activated carbon addition affects substrate $\mathrm{pH}$ and germination of six plant species. Soil Biol Biochem 42:1165-1167

Keane RM, Crawley MJ (2002) Exotic plant invasions and the enemy release hypothesis. Trends Ecol Evol 17:164-170

Kempel A, Chrobock T, Fischer M, Rohr R, van Kleunen M (2013) Determinants of plant establishment success in a multispecies introduction experiment with native and alien species. Proc Natl Acad Sci 110:12727-12732

Lau JA, Puliafico KP, Kopshever JA, Steltzer H, Jarvis E, Schwarzländer M, Strauss S, Hufbauer R (2008) Inference of allelopathy is complicated by effects of activated carbon on plant growth. New Phytol 178:412-423

Levine JM (2000) Species diversity and biological invasions: relating local process to community pattern. Science 288 : $852-854$

Levine MJ, Adler PB, Yelenik SG (2004) A meta-analysis of biotic resistance to exotic plant invasions. Ecol Lett 7:975-989

Li B, Hsu PS, Chen JK (2001) Perspectives on general trends of plant invasions with special reference to alien weed flora of Shanghai. Chinese Biodivers Sci 9:446-457
Li YZ, Yin X, Wei W, Yang EY, hang Y, Tian ZH, Da LJ (2010) Inhibition of local plant Phragmites communis on the invasive plant Solidago canadensis. Acta Ecol Sin 30:6881-6891

Liao H, Luo W, Peng S, Callaway RM (2015) Plant diversity, soil biota and resistance to exotic invasion. Divers Distrib 21: 826-835

Liebman MS (2006) Seed mass affects the susceptibility of weed and crop species to phytotoxins extracted from red clover shoots. Weed Sci 54:340-345

Lou Y, Davis A, Yannarell A (2016) Interactions between allelochemicals and the microbial community affect weed suppression following cover crop residue incorporation into soil. Plant Soil 399:357-371

Marraffini ML, Geller JB (2015) Species richness and interacting factors control invasibility of a marine community. Proc R Soc B Biol Sci 282:151-157

Michelan TS, Thomaz SM, Bini LM (2013) Native macrophyte density and richness affect the invasiveness of a tropical Poaceae species. PLoS One 8:e60004

Naeem S, Knops JMH, Tilman D, Howe KM, Kennedy T, Gale S (2000) Plant diversity increases resistance to invasion in the absence of covarying extrinsic factors. Oikos 91:97-108

Ning L, Yu F-H, van Kleunen M (2016) Allelopathy of a native grassland community as a potential mechanism of resistance against invasion by introduced plants. Biol Invasions 18: 3481-3493

Ortega YK, Pearson DE (2005) Weak vs. strong invaders of natural plant communities: assessing invasibility and impact. Ecol Appl 15:651-661

Parker C, Riches CR (1993) Parasitic weeds of the world: biology and control. CAB international, Wallingford, England

Parsons W, Cuthbertson E (2001) Noxious weeds of Australia. CSIRO Publishing, Collingwood

Pearson D, Ortega Y, Eren O, Hierro J (2018) Community assembly theory as a framework for biological invasions. Trends Ecol Evol 33:313-325

Petruzzella A, Manschot J, van Leeuwen C, Grutters B, Bakker E (2018) Mechanisms of invasion resistance of aquatic plant communities. Front Plant Sci 9:134

Prati D, Bossdorf O (2004) Allelopathic inhibition of germination by Alliaria petiolata (Brassicaceae). Am J Bot 91:285-288

Qin R-M, Zheng Y-L, Valiente-Banuet A, Callaway R, Barclay G, Silva Pereyra C, Feng Y-L (2013) The evolution of increased competitive ability, innate competitive advantages, and novel biochemical weapons act in concert for a tropical invader. New Phytol 197:979-988

Rabotnov TA (1982) Importance of the evolutionary approach to the study of allelopathy. Ekologia 3:5-8

Ridenour W, Callaway R (2001) The relative importance of allelopathy in interference: the effects of an invasive weed on a native bunchgrass. Oecologia 126:444-450

SAS Institute Inc. (2004) SAS/STAT 9.1 User's Guide. Cary, North Carolina, USA

Schmidt SK, Ley RE (1999) Microbial competition and soil structure limit the expression of phytochemicals in nature. In: In principles and practices in plant ecology: allelochemical interactions. CRC Press, Boca Raton

Sokal RR, Rohlf FJ (1995) Biometry. W. H. Freeman and Company, New York

Song Y-B, Yu F-H, Keser LJ, Dawson W, Fischer M, Dong M, van Kleunen M (2013) United we stand, divided we fall: a meta- 
analysis of experiments on clonal integration and its relationship to invasiveness. Oecologia 171:317-327.

Stohlgren T, Barnett D, Kartesz J (2003) The rich get richer: patterns of plant invasions in the United States. Front Ecol Environ 1:11-14

Sun Y, Mueller-Schaerer H, Maron JL, Schaffner U (2015) Origin matters: diversity affects the performance of alien invasive species but not of native species. Am Nat 185:725-736

Tan J, Pu Z, Ryberg W, Jiang L (2015) Resident-invader phylogenetic relatedness, not resident phylogenetic diversity, controls community invasibility. Am Nat 186:59-71

Teixeira MC, Bini LM, Thomaz SM (2017) Biotic resistance buffers the effects of nutrient enrichment on the success of a highly invasive aquatic plant. Freshw Biol 62:65-71

Theoharides KA, Dukes JS (2007) Plant invasion across space and time: factors affecting nonindigenous species success during four stages of invasion. New Phytol 176:256-273

Tollenaar M, Dibo A, Aguilara A, Weise S, Swanton C (1994) Effect of crop density on weed interference in maize. Agron J $86: 591-595$

Turnbull L, Jonathan M, Fergus A, Petermann J (2010) Species diversity reduces invasion success in pathogen-regulated communities. Oikos 119:1040-1046

van Kleunen M, Maurel N, Dawson W (2015) Characteristics of successful alien plants. Mol Ecol 24:1954-1968

van Kleunen M, Bossdorf O, Dawson M (2018) The ecology and evolution of alien plants. Annu Rev Ecol Evol Syst 49:25-47

van Ruijven J, De Deyn GB, Berendse F (2003) Diversity reduces invasibility in experimental plant communities: the role of plant species. Ecol Lett 6:910-918

Vojik M, Boublik K (2018) Fear of the dark: decline in plant diversity and invasion of alien species due to increased tree canopy density and eutrophication in lowland woodlands. Plant Ecol 219:749-758

Wang Y-J, Müller-Schärer H, van Kleunen M, Cai A-M, Zhang P, Yan R, Dong B-C, Yu F-H (2017) Invasive alien plants benefit more from clonal integration in heterogeneous environments than natives. New Phytol 216:1072-1078
Wardle DA (2001) Experimental demonstration that plant diversity reduces invasibility - evidence of a biological mechanism or a consequence of sampling effect? Oikos 95:161-170

Wardle DA, Nilsson MC, Gallet C, Ackrisson OZ (1998) An ecosystem-level perspective of allelopathy. Biol Rev 73: 305-319

Weidenhamer JD, Romeo JT (2005) Allelochemicals as a mechanism for resisting invasion: the case of Polygonella myriophylla. In: Inderjit (ed) Invasive plants: ecological and agricultural aspects. Birkhäuser Basel, Switzerland

Weidenhamer JD, Hartnett DC, Romeo JT (1989) Densitydependent phytotoxicity: distinguishing resource competition and allelopathic interference in plants. J Appl Ecol 26: 613-624

Weißhuhn K, Prati D (2009) Activated carbon may have undesired side effects for testing allelopathy in invasive plants. Basic Appl Ecol 10:500-507

Wu H, Carrillo J, Ding J (2017) Species diversity and environmental determinants of aquatic and terrestrial communities invaded by Alternanthera philoxeroides. Sci Total Environ 581:666-675

Wurst S, Vendor V, Rillig M (2010) Testing for allelopathic effects in plant competition: does activated carbon disrupt plant symbioses? Plant Ecol 211:19-26

Zak D, Holmes W, White D, Peacock A, Tilman D (2003) Plant diversity, soil microbial communities, and ecosystem function: are there any links? Ecology 84:2042-2050

Zhang S, Jin Y, Tang J, Chen X (2009) The invasive plant Solidago canadensis L. suppresses local soil pathogens through allelopathy. Appl Soil Ecol 41:215-222

Zhu D, Wang P, Zhang W, Yuan Y, Li B, Wang J (2015) Sampling and complementarity effects of plant diversity on resource use increases the invasion resistance of communities. PLoS One 10:e 0141559 